\title{
Atributos químicos do solo, crescimento radicular e produtividade do arroz de acordo com a aplicação de escórias
}

\author{
Juliana Garcia Carvalho-Pupatto(1), Leonardo Theodoro Büll(2) e Carlos Alexandre Costa Crusciol(1)
}

(1)Universidade Estadual Paulista (Unesp), Faculdade de Ciências Agronômicas (FCA), Dep. de Produção Vegetal, Caixa Postal 237, CEP 18603-970 Botucatu, SP. E-mail: crusciol@fca.unesp.br (2)Unesp, FCA, Dep. de Recursos Naturais. E-mail: bull@fca.unesp.br

\begin{abstract}
Resumo - Resíduos industriais são fontes alternativas de nutrientes para as plantas e sua utilização decorre da necessidade de diminuir o acúmulo dos resíduos nos centros de produção. O objetivo deste trabalho foi avaliar o efeito de escórias de siderurgia nos atributos químicos do solo, no desenvolvimento e na produtividade de grãos do arroz de terras altas irrigado por aspersão. O delineamento experimental foi em blocos casualizados, com três tratamentos constituídos de duas escórias, alto-forno (196 $\mathrm{g} \mathrm{kg}^{-1}$ de $\left.\mathrm{Si}\right)$ e aciaria $\left(56 \mathrm{~g} \mathrm{~kg}^{-1}\right.$ de $\left.\mathrm{Si}\right)$, e a testemunha sem aplicação, com oito repetições. As escórias podem ser usadas como corretivo de acidez do solo e como fonte de silício. As alterações nos atributos químicos do solo estão relacionadas com a composição química das escórias. A escória de alto-forno proporcionou maior crescimento radicular em profundidade e melhor distribuição no perfil do solo e, conseqüentemente, maior produção de massa de matéria seca da parte aérea e produtividade de grãos de arroz.
\end{abstract}

Termos para indexação: Oryza sativa, resíduo industrial, comprimento radicular, acidez, silício.

\section{Soil chemical attributes, root growth and rice yield according to slag application}

\begin{abstract}
Use of industrial residues as alternative sources of nutrients to the plants is due to the necessity of reducing their accumulation in the production sites. The objective of this work was to evaluate the effect of metallurgy slag in soil chemical attributes, in development and in grain yield of upland rice sprinkler irrigated. The experiment was carried out in a randomized block design, with three treatments constituted by two scums, blast furnace (196 g kg${ }^{-1}$ of Si) and steel slag $\left(56 \mathrm{~g} \mathrm{~kg}^{-1}\right.$ of $\left.\mathrm{Si}\right)$, and a control without application, with eight replications. The scums can be used as corrective of soil acidity and silicon source. Alterations in the soil chemical attributes are related to the chemical composition of the scums. Blast furnace slag resulted in higher root growth in depth and better distribution in the profile soil provides higher shoot dry matter yield and grain yield.
\end{abstract}

Index terms: Oryza sativa, industrial residue, root length, acidity, silicon.

\section{Introdução}

O aproveitamento agrícola de resíduos industriais como a escória de siderurgia é pouco utilizado no Brasil, apesar da grande quantidade disponível, aproximadamente 3 milhões de toneladas anualmente. Em várias partes do mundo, porém, esse processo é estudado e utilizado (Prado \& Fernandes, 2001).

Escórias são resíduos da indústria da fundição do aço e do ferro-gusa. A escória de alto-forno é o resíduo do processo siderúrgico que tem como primeira etapa a obtenção do ferro bruto e impuro - ferro-gusa - por meio da redução do minério de ferro, enquanto a escória de aciaria é obtida no processo de produção do aço pela utilização do ferro-gusa, processo que exige menor grau de impureza (Prado et al., 2001). Na sua composição encontram-se diversos óxidos de $\mathrm{Ca}, \mathrm{Mg}, \mathrm{Si}, \mathrm{Fe}$ e Mn, cujas quantidades e concentrações são decorrentes da constituição química da matéria-prima (minério de ferro, carvão, calcário ou cal) utilizada no processo de fabricação do produto, além do tipo de refratário usado na parede do forno (Prado et al., 2001). O teor de Si total das escórias no Brasil varia conforme o tipo, sendo que a escória proveniente de aciaria apresenta entre 12 a 22 dag $\mathrm{kg}^{-1}$, enquanto a escória de alto-forno, entre 36 a 42 dag kg $^{-1}$ (Piau, 1995)

Estudos com escórias aplicadas ao solo têm demonstrado aumento de $\mathrm{pH}$ e redução do $\mathrm{H}+\mathrm{Al}$ (Prado \& 
Fernandes, 2000, 2003), em razão da presença de agente neutralizante da acidez como o $\mathrm{SiO}_{3}{ }^{-2}$ (Alcarde, 1992), incrementos na disponibilidade de P (Prado et al., 2002), $\mathrm{Ca}, \mathrm{Mg}$ (Prado \& Fernandes, 2000, 2003) e Si no solo (Anderson et al., 1987; Winslow, 1992), o que, para culturas acumuladoras de Si como o arroz e a cana-deaçúcar (Korndörfer \& Datnoff, 1995), tem refletido em tolerância a doenças e aumentos de produtividade.

$\mathrm{O}$ aumento nos teores de $\mathrm{Ca}$ e $\mathrm{Mg}$ no solo em razão da utilização da escória pode apresentar efeito positivo no desenvolvimento de raízes, especialmente em relação ao Ca, uma vez que são bem conhecidos os efeitos positivos deste elemento no crescimento radicular (Caires et al., 2001).

O objetivo deste trabalho foi avaliar o efeito de escórias de siderurgia nos atributos químicos do solo, no desenvolvimento e na produtividade de grãos do arroz de terras altas irrigado por aspersão.

\section{Material e Métodos}

O trabalho foi realizado no ano agrícola de 1998/1999, na Fazenda Experimental São Manuel, Município de São Manuel, pertencente à Faculdade de Ciências Agronômicas (FCA), Campus de Botucatu/Unesp (latitude $22^{\circ} 45^{\prime} \mathrm{S}$, longitude $48^{\circ} 34^{\prime} \mathrm{W}$, altitude de $\left.750 \mathrm{~m}\right)$. O clima predominante na região é do tipo Cwa (Köeppen), ou seja, clima tropical de altitude, com inverno seco e verão quente e chuvoso (Lombardi Neto \& Drugowich, 1994).

O solo da área experimental é classificado como Latossolo Vermelho distroférrico, textura média, com as seguintes características químicas: $\mathrm{pH}, 5,3 ; \mathrm{MO}, 8 \mathrm{~g} \mathrm{dm}^{-3}$; P-resina, $7 \mathrm{mg} \mathrm{dm}^{-3}$; 1,3, 12, 6, 12, 19 e $31 \mathrm{mmol}_{\mathrm{c}} \mathrm{dm}^{-3}$, respectivamente, de $\mathrm{K}^{+}, \mathrm{Ca}^{2+}, \mathrm{Mg}^{2+}, \mathrm{H}+\mathrm{Al}, \mathrm{SB}$ e CTC; 0,14, 0,6, 10, 2,7, 0,3 e 5,9 $\mathrm{mg} \mathrm{dm}^{-3}$, respectivamente, de B, $\mathrm{Cu}, \mathrm{Fe}, \mathrm{Mn}, \mathrm{Zn}$ e Si; e V, 61\%. Quanto à caracterização física, o solo apresenta $810 \mathrm{~g} \mathrm{~kg}^{-1}, 190 \mathrm{~g} \mathrm{~kg}^{-1} \mathrm{e} 0 \mathrm{~g} \mathrm{~kg}^{-1}$, respectivamente, de areia, argila e silte.

O delineamento experimental empregado foi o de blocos casualizados, com oito repetições. Os tratamentos foram constituídos de duas fontes de Si, sendo duas escórias, alto-forno (196 g kg${ }^{-1}$ de Si) e aciaria $\left(56 \mathrm{~g} \mathrm{~kg}^{-1} \mathrm{de} \mathrm{Si}\right)$, na dose de $1.000 \mathrm{~kg} \mathrm{ha}^{-1}$ de $\mathrm{Si}$, e a testemunha, sem aplicação. As características químicas dos materiais utilizados são apresentadas na Tabela 1.

A aplicação das escórias foi a lanço e posteriormente incorporadas ao solo, na profundidade de 0 a $20 \mathrm{~cm}$, mediante grade aradora. Após cinco dias, foi feita a semeadura do arroz (cultivar IAC-202).

Por ocasião da semeadura aplicaram-se $270 \mathrm{~kg} \mathrm{ha}^{-1} \mathrm{da}$ fórmula 4-30-10, conforme Cantarella \& Furlani (1996). Foram realizadas três adubações de cobertura, a primeira no perfilhamento (fase vegetativa), com $30 \mathrm{~kg} \mathrm{ha}^{-1} \mathrm{de} \mathrm{Ne}$ $13 \mathrm{~kg} \mathrm{ha}^{-1}$ de $\mathrm{K}_{2} \mathrm{O}$, a segunda no ponto de algodão (fase reprodutiva), com $30 \mathrm{~kg} \mathrm{ha}^{-1}$ de $\mathrm{Ne} 15 \mathrm{~kg} \mathrm{ha}^{-1}$ de $\mathrm{K}_{2} \mathrm{O}$ e a terceira no emborrachamento (fase reprodutiva), com $30 \mathrm{~kg} \mathrm{ha}^{-1}$ de $\mathrm{N}$ e $30 \mathrm{~kg} \mathrm{ha}^{-1}$ de $\mathrm{K}_{2} \mathrm{O}$, utilizando sulfato de amônio e cloreto de potássio.

As parcelas eram formadas de 10 linhas de $5 \mathrm{~m}$ de comprimento, sendo desprezadas duas linhas laterais e $0,5 \mathrm{~m}$ de cada extremidade. A irrigação foi realizada utilizando um sistema por aspersão convencional quando os tensiômetros indicavam $35,5 \mathrm{kPa}$ de tensão.

$\mathrm{O}$ desenvolvimento radicular foi avaliado quando as plantas encontravam-se em pleno florescimento e a sua amostragem foi realizada utilizando-se um trado de aço galvanizado com diâmetro de $4,5 \mathrm{~cm}$. As amostras foram coletadas nas profundidades de 0-10, 10-20, 20-30 e $30-50 \mathrm{~cm}$. As raízes foram separadas do solo por lavagem em água corrente sobre peneira de $0,5 \mathrm{~mm}$. O material lavado e separado foi acondicionado em coletor universal com uma solução $70 \%$ de álcool e $30 \%$ de água e levado à geladeira a uma temperatura de $4^{\circ} \mathrm{C}$.

As variáveis que caracterizaram o desenvolvimento radicular foram determinadas em um Scanner acoplado a um computador dotado do Software WinRhizo, que utiliza como princípio o método proposto por Tennant (1975). Nesse equipamento determinou-se o comprimento $\left(\mathrm{km} \mathrm{m}^{-3}\right)$, a superfície $\left(\mathrm{m}^{2} \mathrm{~m}^{-3}\right)$ e o volume radicular $\left(\mathrm{dm}^{-3} \mathrm{~m}^{-3}\right)$. Após essas avaliações as amostras foram secadas em estufa a $65^{\circ} \mathrm{C}$, para posteriormente determinar-se a produção de matéria seca radicular $\left(\mathrm{g} \mathrm{m}^{-3}\right)$.

Tabela 1. Composição química das escórias de alto-forno e aciaria.

\begin{tabular}{|c|c|c|c|c|c|c|c|c|c|c|}
\hline Escória & $\mathrm{P}$ & $\mathrm{K}$ & $\mathrm{Ca}$ & $\mathrm{Mg}$ & S & $\mathrm{Na}$ & $\mathrm{Fe}$ & $\mathrm{Mn}$ & $\mathrm{Al}$ & $\mathrm{Si}$ \\
\hline Alto-forno & 0,2 & 9 & 219 & 55 & 1,3 & 1,8 & 16 & 23 & 62 & 196 \\
\hline Aciaria & 6,2 & - & 273 & 63 & 0,8 & & 243 & 47 & 3 & 56 \\
\hline
\end{tabular}

Pesq. agropec. bras., Brasília, v.39, n.12, p.1213-1218, dez. 2004 
Nas avaliações dos atributos químicos do solo foram coletadas cinco subamostras para formarem uma amostra composta por parcela.

No momento da colheita avaliou-se a produtividade de matéria seca da parte aérea $\left(\mathrm{kg} \mathrm{ha}^{-1}\right)$, a produtividade de grãos $\left(\mathrm{kg} \mathrm{ha}^{-1}\right)$ e os atributos químicos do solo $\left(\mathrm{pH}, \mathrm{H}+\mathrm{Al}, \mathrm{K}^{+}, \mathrm{Ca}^{2+}, \mathrm{Mg}^{2+}\right.$ e $\mathrm{Si}$ ) na profundidade 0-20 cm, conforme Korndörfer et al. (1999) e Raij et al. (2001).

Os resultados obtidos foram submetidos à análise de variância e as médias comparadas pelo teste DMS a 5\% de probabilidade.

\section{Resultados e Discussão}

A utilização de escórias elevou de forma significativa os valores de $\mathrm{pH}$ e reduziu a acidez potencial $(\mathrm{H}+\mathrm{Al})$ do solo em relação ao tratamento testemunha (sem aplicação de escória) (Tabela 2). Resultados semelhantes com o uso de escórias foram relatados por Ribeiro et al. (1986), Prado \& Fernandes $(2000,2003)$ e Prado et al. (2002), sendo atribuído à ação do agente neutralizante $\mathrm{SiO}_{3}{ }^{-2}$ gerado pela reação das escórias com o solo (Alcarde, 1992).

Os valores de $\mathrm{pH}$ e $\mathrm{H}+\mathrm{Al}$ diferiram entre as escórias, apesar de o cálculo ter sido feito de modo a receber a mesma quantidade de silício, ou seja, $1.000 \mathrm{~kg} \mathrm{ha}^{-1}$, o

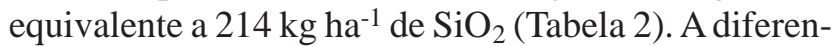
ça constatada entre as fontes para esses atributos químicos $(\mathrm{pH}$ e $\mathrm{H}+\mathrm{Al})$ pode estar relacionada ao PRNT dos materiais, uma vez que Carvalho (2000) verificou para escória de alto-forno e de aciaria, valores de $39 \%$ e $60 \%$, respectivamente.

$\mathrm{O}$ teor de $\mathrm{K}$ no solo foi maior no tratamento que recebeu escória de alto-forno, em razão desse resíduo apresentar o elemento na sua constituição.

A aplicação de escória de aciaria proporcionou maiores teores de $\mathrm{Ca}$ e $\mathrm{Mg}$ no solo, diferindo da escória de alto-forno e da testemunha, que, por sua vez, não diferi- ram entre si (Tabela 2). Essa diferença ocorre porque a escória de aciaria contém maior teor de $\mathrm{Ca}$ e $\mathrm{Mg}$ que a escória de alto-forno, além de possuir menor teor de $\mathrm{Si}$, necessitando, dessa forma, de maiores quantidades do produto para fornecer a mesma quantidade de silício. A utilização de diferentes fontes de escória proporcionou aumentos nos teores de Si no solo, sendo mais pronunciado com a aplicação da escória de aciaria, que diferiu significativamente da de alto-forno.

Quanto ao comprimento radicular, houve diferença entre as escórias e entre os tratamentos escória de altoforno e a testemunha, na profundidade de $0-10 \mathrm{~cm}$, enquanto na profundidade de 10-20 cm verificou-se diferença entre todos os tratamentos (Figura 1). Nas profundidades de 20-30 e 30-50 cm, houve diferenças entre as escórias e entre a escória de alto-forno e a testemunha.

A escória de aciaria apresentou os melhores resultados em relação aos atributos químicos do solo $(\mathrm{pH}, \mathrm{H}+\mathrm{Al}$, $\mathrm{Ca}, \mathrm{Mg}$, e $\mathrm{Si}$ ) na camada de $0-20 \mathrm{~cm}$, exceto quanto aos teores de potássio. Os teores de $\mathrm{K}$ não contribuíram para um maior crescimento radicular nessa camada, nem nas camadas subsuperficiais $(20-50 \mathrm{~cm})$, onde a escória de alto-forno proporcionou os maiores valores para crescimento radicular (Figura 1). Esse padrão de desenvolvimento do sistema radicular pode estar relacionado a uma menor absorção de $\mathrm{K}$, que reduziu o crescimento no perfil amostrado, visto que com a aplicação da escória de aciaria, as relações, tanto de $\mathrm{Ca} / \mathrm{K}$ (48:1) quanto de $\mathrm{Mg} / \mathrm{K}$ (16:1) foram elevadas (Andreotti, 1998) e bem superiores às propiciadas pela escória de altoforno $(\mathrm{Ca} / \mathrm{K}=16: 1$ e $\mathrm{Mg} / \mathrm{K}=8: 1)$.

As altas relações $\mathrm{Ca} / \mathrm{K}$ e $\mathrm{Mg} / \mathrm{K}$ no tratamento com escória de aciaria, provavelmente, foram mantidas em profundidade por meio da lixiviação das bases (K, Ca e $\mathrm{Mg}$ ), uma vez que o solo apresenta granulometria favorável a esse mecanismo de carregamento de íons, sendo ainda favorecido pelo sistema de cultivo do arroz sob irrigação por aspersão. Além disso, os baixos teores de

Tabela 2. Resultados das análises químicas das amostras de solo (0-0,20 m) coletadas por ocasião da colheita do arroz em razão dos tratamentos ${ }^{(1)}$.

\begin{tabular}{lcccccc}
\hline Tratamento & $\begin{array}{c}\mathrm{pH} \\
\left(\mathrm{CaCl}_{2}\right)\end{array}$ & $\mathrm{H}+\mathrm{Al}$ & $\mathrm{K}^{+}$ & $\mathrm{Ca}^{2+}$ & $\mathrm{Mg}^{2+}$ & $\begin{array}{c}\text { Si-Solo } \\
\left(\mathrm{mg} \mathrm{dm}^{-3}\right)\end{array}$ \\
\hline Escória de alto-forno & $6,2 \mathrm{~b}$ & $-13 \mathrm{~b}$ & $1,8 \mathrm{a}$ & $29 \mathrm{~b}$ & $15 \mathrm{~b}$ & $42 \mathrm{~b}$ \\
Escória de aciaria & $7,0 \mathrm{a}$ & $9 \mathrm{c}$ & $1,5 \mathrm{~b}$ & $72 \mathrm{a}$ & $24 \mathrm{a}$ & $59 \mathrm{a}$ \\
Sem aplicação & $5,7 \mathrm{c}$ & $17 \mathrm{a}$ & $1,4 \mathrm{~b}$ & $15 \mathrm{~b}$ & $9 \mathrm{~b}$ & $6 \mathrm{c}$ \\
\hline $\mathrm{CV}(\%)$ & 6,9 & 11,0 & 14,8 & 32,5 & 43,4 & 20,6
\end{tabular}

${ }^{(1)}$ Médias seguidas de mesma letra não diferem entre si pelo teste DMS a 5\% de probabilidade. 
K no solo restringiram o crescimento radicular do arroz (Crusciol et al., 2002).

$\mathrm{O}$ menor desenvolvimento do sistema radicular no tratamento testemunha, na camada de $30-50 \mathrm{~cm}$, comparado ao que recebeu escória de alto-forno (Figura 1), deve-se às baixas relações $\mathrm{Ca} / \mathrm{K}(11: 1)$ e $\mathrm{Mg} / \mathrm{K}(6: 1)$ nas camadas superficiais, que podem ter reduzido a $a b-$ sorção de $\mathrm{Ca}$ e $\mathrm{Mg}$ e, conseqüentemente, o crescimento radicular, uma vez que ambos elementos são componentes dos pectatos que constituem a parede celular (Malavolta, 1980). Segundo Büll et al. (1993), raízes de monocotiledôneas como o arroz apresentam baixa CTC radicular, tendo preferência na absorção de cátions monovalentes, como o potássio. Desta forma, torna-se necessário um suprimento adequado de $\mathrm{Ca}$ e $\mathrm{Mg}$ no solo, de modo que esses elementos possam competir por sítios de ligação no sistema radicular, uma vez que a planta preferencialmente absorve $\mathrm{K}$, o qual inibe de for- ma competitiva a absorção de Ca e magnésio.

A superfície e o volume radicular apresentaram as mesmas tendências de resposta aos tratamentos, exceção feita à camada de $0-10 \mathrm{~cm}$, em que não houve diferença da superfície radicular entre os tratamentos escória de alto-forno e a testemunha, ao passo que, em relação ao volume radicular, esses tratamentos apresentaram diferenças (Figura 1). Em ambas as variáveis não houve diferença entre as escórias nesta camada, porém a escória de aciaria diferiu da testemunha. Nas profundidades de $10-20 \mathrm{~cm}$ e $20-30 \mathrm{~cm}$ não houve diferença entre os tratamentos, enquanto na profundidade de 30-50 cm, o tratamento com escória de alto-forno diferiu dos demais, os quais, por sua vez, não diferiram entre si (Figura 1).

A produção de massa de matéria seca de raiz na camada de $0-10 \mathrm{~cm}$ não apresentou diferença entre as escórias, mas ambas diferiram da testemunha (Figu-
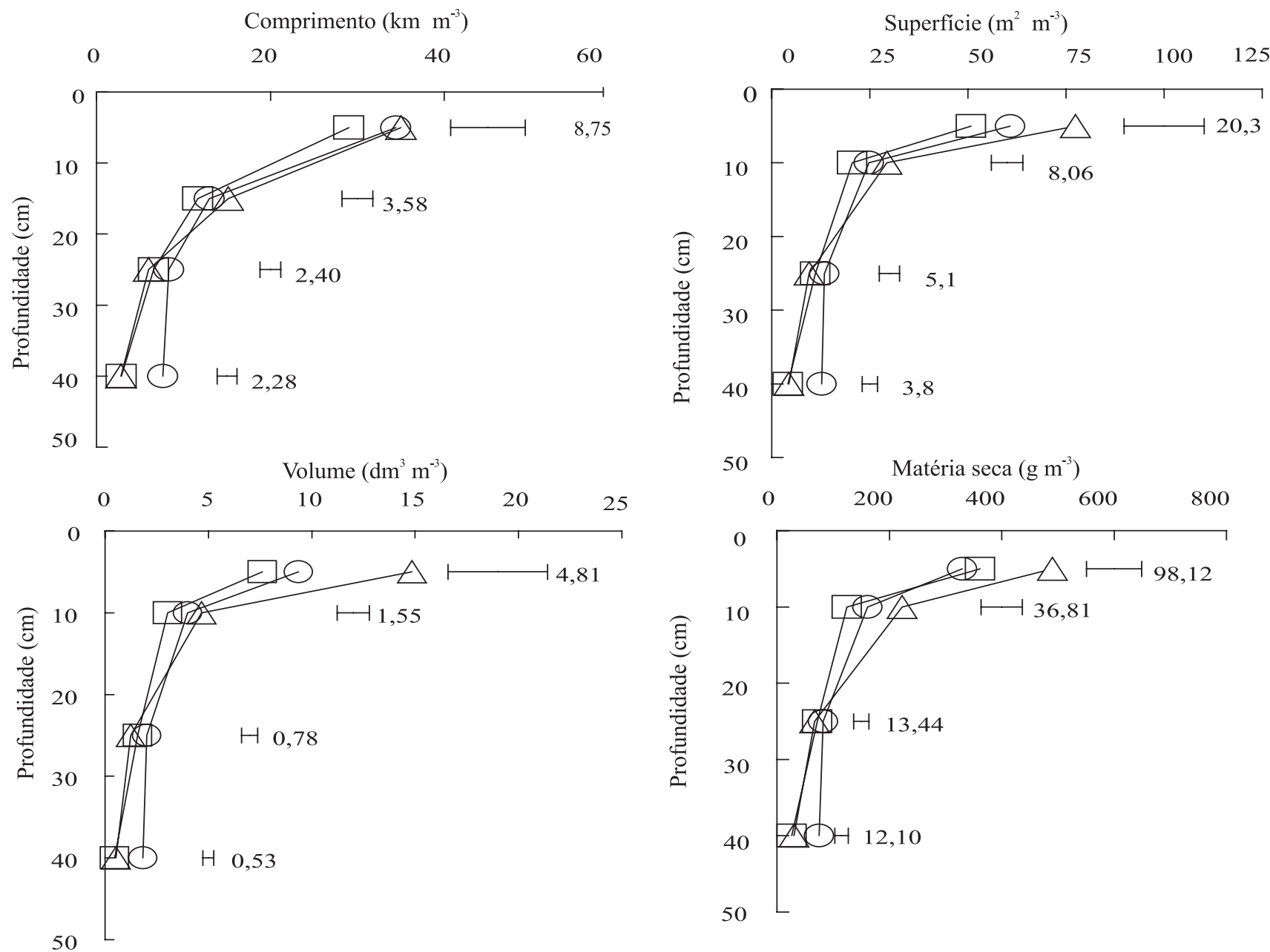

Figura 1. Comprimento, superfície, volume e matéria seca radicular do arroz de terras altas irrigado por aspersão, em função da aplicação de escórias de alto-forno $(\bigcirc)$, aciaria $(\square)$ e sem aplicação $(\triangle)$. Barras horizontais em cada ponto representam a diferença mínima significativa a 5\% de probabilidade pelo teste DMS. 
ra 1). Na profundidade de $10-20 \mathrm{~cm}$ houve diferença apenas entre o tratamento escória de aciaria e a testemunha. Na profundidade de $20-30 \mathrm{~cm}$ não houve diferença entre os tratamentos, porém, na de $30-50 \mathrm{~cm}$, o tratamento com escória de alto-forno diferiu dos demais, os quais, por sua vez, não diferiram entre si.

As características morfológicas das raízes que apresentam maiores influências no processo de absorção são o comprimento e o diâmetro (Rosolem, 1995).

Dessa forma, ao analisar o porcentual do sistema radicular por meio do comprimento, constata-se, no perfil amostrado, melhor uniformidade na distribuição com a aplicação da escória de alto-forno em relação aos demais tratamentos, apresentando, nitidamente, maior porcentagem de raízes na profundidade de $30-50 \mathrm{~cm}$ (Figura 2). Esse resultado é decorrente da escória de altoforno ter proporcionado maior comprimento total de raízes na camada mais profunda $(30-50 \mathrm{~cm})$. Assim, como o comprimento total, no perfil amostrado, em todos os tratamentos, foi considerado $100 \%$, houve maior porcentagem de raízes na maior profundidade no tratamento com escória de alto-forno, o que diminuiu do total a porcentagem nas camadas superficiais $(0-10 \mathrm{~cm} \mathrm{e}$ $10-20 \mathrm{~cm}$ ) em relação aos demais tratamentos, não significando menor comprimento (Figura 1).

Esses resultados podem ter refletido na produção de massa de matéria seca da parte aérea e na produtividade de grãos, cujos maiores valores foram alcançados no tratamento que recebeu escória de alto-forno (Tabela 3). O maior crescimento em profundidade aliado à melhor distribuição do sistema radicular no perfil amostrado propi-

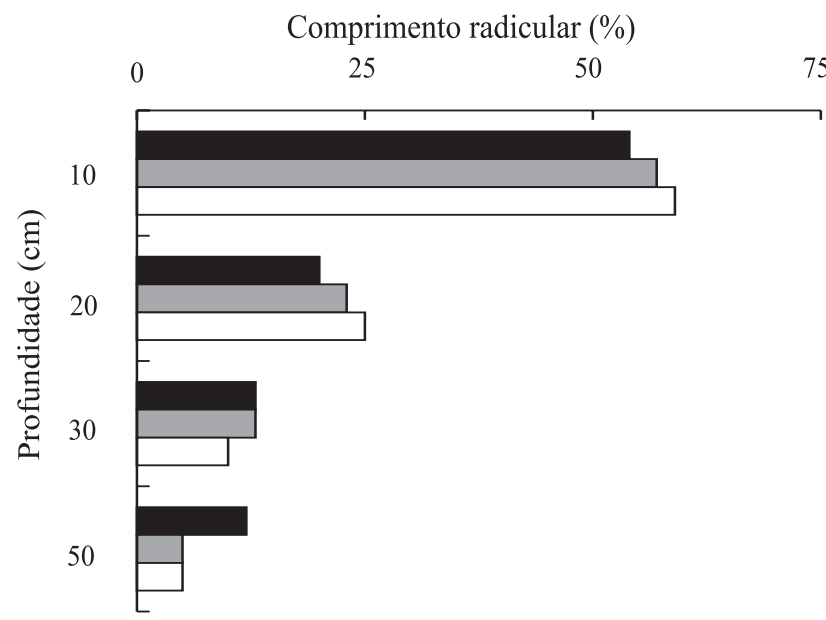

Figura 2. Distribuição do comprimento radicular do arroz de terras altas irrigado por aspersão, em função da aplicação de

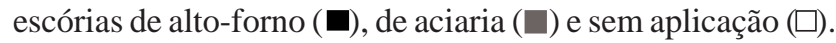

Tabela 3. Matéria seca de parte aérea e produtividade de grãos do arroz de terras altas irrigado por aspersão, em razão dos tratamentos $^{(1)}$.

\begin{tabular}{lcc}
\hline Tratamento & $\begin{array}{c}\text { Matéria seca } \\
\text { da parte aérea }\end{array}$ & $\begin{array}{c}\text { Produtividade } \\
\text { de grãos }\end{array}$ \\
\hline Escória de alto-forno & $8.625 \mathrm{a}$ & $5.491 \mathrm{a}$ \\
Escória de aciaria & $6.875 \mathrm{~b}$ & $4.654 \mathrm{ab}$ \\
Sem aplicação & $7.650 \mathrm{ab}$ & $4.552 \mathrm{~b}$ \\
\hline $\mathrm{CV}(\%)$ & 21,0 & 16,7 \\
\hline
\end{tabular}

${ }^{(1)}$ Médias seguidas de mesma letra não diferem entre si pelo teste DMS a $5 \%$ de probabilidade.

ciou às plantas exploração de maior volume de solo, tendo como conseqüência, provavelmente, maior absorção de nutrientes, tanto os de maior mobilidade, como o $\mathrm{N}$, que facilmente é lixiviado, atingindo as camadas mais profundas, o que nas condições experimentais provavelmente deve ter ocorrido por causa do tipo de solo e do sistema de cultivo irrigado por aspersão, como os nutrientes de menor mobilidade, como o fósforo (Sousa et al., 1996).

\section{Conclusões}

1. As escórias podem ser usadas como corretivo de acidez do solo e como fonte de silício.

2. As alterações nos atributos químicos do solo estão relacionadas com a composição química das escórias.

3. A escória de alto-forno proporciona maior crescimento radicular em profundidade e melhor distribuição no perfil do solo e, conseqüentemente, maior produção de massa de matéria seca da parte aérea e produtividade de grãos de arroz.

\section{Referências}

ALCARDE, J.C. Corretivo de acidez do solo: características e interpretações. São Paulo: Associação Nacional para Difusão de Adubos e Corretivos Agrícolas, 1992. 26p. (Boletim Técnico, 6).

ANDERSON, D.L.; JONES, D.B.; SNYDER, G.H. Response of a rice-surgarcane rotation to calcium silicate slag on everglades histosols. Agronomy Journal, v.79, p.531-535, 1987.

ANDREOTTI, M. Resposta do milho ao potássio em função da saturação por bases do solo. 1998. 85p. Tese (Doutorado) Universidade Estadual Paulista, Botucatu.

BÜlL, L.T.; MELlO, A.F.; SOARES, E.; BOARETO, A.E. Influência da relação $\mathrm{K} /(\mathrm{Ca}+\mathrm{Mg})$ do solo na produção de matéria seca e na absorção de potássio por gramíneas e leguminosas forrageiras: I. Absorção de potássio em função da espécie vegetal. Cientifica, v.21, p.55-66, 1993. 
CAIRES, E.F.; FONSECA, A.F.; FELDHAUS, I.C.; BLUM, J. Crescimento radicular e nutrição da soja cultivada no sistema plantio direto em resposta ao calcário e gesso na superfície. Revista Brasileira de Ciência do Solo, v.25, p.1029-1040, 2001.

CANTARELLA, H.; FURLANI, P.R. Arroz de sequeiro. In: RAIJ, B. van; CANTARELLA, H.; QUAGGIO, J.A.; FURLANI, A.M.C. (Ed.). Recomendações de adubação e calagem para o Estado de São Paulo. 2.ed. Campinas: IAC, 1996. p.48-49. (Boletim Técnico, 100).

CARVALHO, J.C. Análise de crescimento e produção de grãos da cultura do arroz irrigado por aspersão em função da aplicação de escórias de siderurgia como fonte de silício. 2000. 119p. Dissertação (Mestrado) - Universidade Estadual Paulista, Botucatu.

CRUSCIOL, C.A.C.; SARTORI, J.E.; ROSA, J.M.O.; SILVA, R.H. Crescimento radicular de cultivares de arroz de terras altas em função da disponibilidade de potássio. In: REUNIÃO NACIONAL DE PESQUISA DE ARROZ, 7., Florianópolis, 2002. Anais. Florianópolis: Embrapa Arroz e Feijão; Epagri, 2002. p.534-537.

KORNDÖRFER, G.H.; COELHO, N.M.; SNYDER, G.H.; MIZUTANI, C.T. Avaliação de métodos de extração de silício em solos cultivados com arroz de sequeiro. Revista Brasileira de Ciência do Solo, v.23, p.101-106, 1999.

KORNDÖRFER, G.H.; DATNOFF, L.E. Adubação com silício: uma alternativa no controle de doenças da cana-de-açúcar e do arroz. Informações Agronômicas, n.70, p.1-3, 1995.

LOMBARDI NETO, F.; DRUGOWICH, M.I. (Coord.). Manual técnico de manejo e conservação de solo e água. Campinas: Coordenadoria de Assistência Técnica Integral, 1994. v.2.

MALAVOLTA, E. Elementos de nutrição mineral de plantas. São Paulo: Agronômica Ceres, 1980. 251p.

PIAU, W.C. Efeito de escória de siderurgia em atributos químicos de solos e na cultura do milho (Zea mays L.). 1995. 124p. Tese (Doutorado) - Escola Superior de Agricultura Luiz de Queiroz, Piracicaba.

PRADO, R. de M.; COUTINHO, E.L.M.; ROQUE, C.G.; VILLAR, M.L.P. Avaliação da escória de siderurgia e de calcários como corretivos da acidez do solo no cultivo da alface. Pesquisa Agropecuária Brasileira, v.37, p.539-546, 2002.

PRADO, R. de M.; FERNANDES, F.M. Efeito da escória de siderurgia e calcário na disponibilidade de fósforo de um Latossolo Vermelho-Amarelo cultivado com cana-de-açúcar. Pesquisa Agropecuária Brasileira, v.36, p.1199-1204, 2001.

PRADO, R. de M.; FERNANDES, F.M. Efeito residual da escória de siderurgia como corretivo da acidez do solo na soqueira da canade-açúcar. Revista Brasileira de Ciência do Solo, v.27, p.287296, 2003.

PRADO, R. de M.; FERNANDES, F.M. Escória de siderurgia e calcário na correção da acidez do solo cultivado com cana-de-açúcar em vaso. Scientia Agrícola, v.57, p.739-744, 2000.

PRADO, R. de M.; FERNANDES, F.M.; NATALE, W. Uso agrícola da escória de siderurgia no Brasil: estudo na cultura da cana-de-açúcar. Jaboticabal: Funep, 2001. 67p.

RAIJ, B. van; ANDRADE, J.C. de; CANTARELLA, H.; QUAGGIO, J.A. (Ed.). Análise química para avaliação da fertilidade de solos tropicais. Campinas: Instituto Agronômico, 2001. 285p.

RIBEIRO, A.C.; FIRME, D.J.; MATTOS, A.C.M. Avaliação da eficiência de uma escória de aciaria como corretivo da acidez do solo. Revista Ceres, v.33, p.242-248, 1986.

ROSOLEM, C.A. Relações solo-planta na cultura do milho. Jaboticabal: Funep, 1995. 53p.

SOUSA, D.M.G. de; LOBATO, E.; REIN, T.A. Uso de gesso agrícola nos solos dos cerrados. Planaltina: Embrapa-CPAC, 1996. 20p. (Circular Técnica, 32).

TENNANT, D. A test of a modified line intersect method of estimating root length. Journal of Ecology, v.63, p.995-1001, 1975.

WINSLON, M.D. Silicon, disease resistance, and yield of rice genotypes under upland cultural conditions. Crop Science, v.32, p.1208-1213, 1992.

Recebido em 30 de junho de 2004 e aprovado em 10 de setembro de 2004 